\title{
Anelastic properties beneath the Niigata-Kobe Tectonic Zone, Japan
}

CrossMark

\author{
Junichi Nakajima ${ }^{1 *}$ and Toru Matsuzawa ${ }^{2}$
}

\begin{abstract}
We estimate the three-dimensional (3D) P-wave attenuation structure beneath the Niigata-Kobe Tectonic Zone (NKTZ), central Japan, using high-quality waveform data from a large number of stations. The obtained results confirm the segmentation of the NKTZ into three regions, as suggested by 3D seismic velocity models, and reveal characteristic structures related to surface deformation, shallow subduction of the Philippine Sea slab, and magmatism. The lower crust beneath the NKTZ west of the Itoigawa-Shizuoka Tectonic Line (ISTL) is overall characterized by distinct high attenuation, whereas the upper crust shows marked high attenuation to the east of the ISTL. Differences in the depths of anelastically weakened parts of the crust probably result in a first-order spatial variation in surface deformation, forming wide (width of $\sim 100 \mathrm{~km}$ ) and narrow (width of 25-40 km) deformation zones on the western and eastern sides of the ISTL, respectively. Many $M \geq 6.5$ earthquakes occur in the upper crust where seismic attenuation in the underlying lower crust varies sharply, suggesting that spatial variations in rates of anelastic deformation in the lower crust result in stress concentration in the overlying brittle crust. We interpret a moderate- to low-attenuation zone located in the lower crust at the northeast of Biwa Lake to reflect low-temperature conditions that are developed locally as a result of shallow subduction of the cold Philippine Sea slab.
\end{abstract}

Keywords: Seismic attenuation, Strain, Surface deformation, Slab, Grain size

\section{Background}

The Niigata-Kobe Tectonic Zone (NKTZ) is a geodetically derived high-strain-rate zone that extends for $\sim 500 \mathrm{~km}(\mathrm{NE}-\mathrm{SW})$ across central Japan (Sagiya et al. 2000) (purple shading in Fig. 1). The NKTZ is contracting in the WNW-ESE direction at a rate of $\sim 10^{7}$ year $^{-1}$, and the contraction rates are a few times higher than those observed in surrounding regions. The high strain rates were first interpreted based on kinematic models, such as a detachment model (Hirahara et al. 1998) and collision models (e.g., Shimazaki and Zhao 2000; Heki and Miyazaki 2001), but these models are unlikely to produce the NKTZ due to the implausible physics required to produce the combination of the observed stress field, inferred mantle flow, and observed fault movement (Iio et al. 2002). Iio et al. (2002, 2004) proposed an alternative model whereby deformation in the weak, ductile lower

\footnotetext{
*Correspondence: nakajima@geo.titech.ac.jp

${ }^{1}$ Earth and Planetary Sciences, School of Science, Tokyo Institute of Technology, Tokyo, Japan

Full list of author information is available at the end of the article
}

crust facilitates the high strain rates along the NKTZ. However, geodetic observations with dense GNSS arrays have revealed regional variations in the width of the NKTZ, ranging from tens kilometers to the east of the Itoigawa-Shizuoka Tectonic Line (ISTL) to $50-100 \mathrm{~km}$ to the west of the ISTL (e.g., Sagiya et al. 2004; Ohzono et al. 2009; Nishimura et al. 2012). These observations suggest that underlying physical mechanisms generating surface deformation are different between the west and east of the ISTL.

Nakajima and Hasegawa (2007) discussed the origin and segmentation of the NKTZ on the basis of seismic velocity structures and suggested that the crustal structure west of the ISTL differs from that east of the ISTL. Jin and Aki (2005) reported a narrow, conspicuous lowcoda attenuation zone west of the ISTL at frequencies less than $4 \mathrm{~Hz}$, whose existence was later corroborated by Carcole and Sato (2010) and Hiramatsu et al. (2013). Shear-wave splitting analysis of the upper crust suggests that the high strain rates at the surface west of the ISTL are caused by high deformation rates below the 


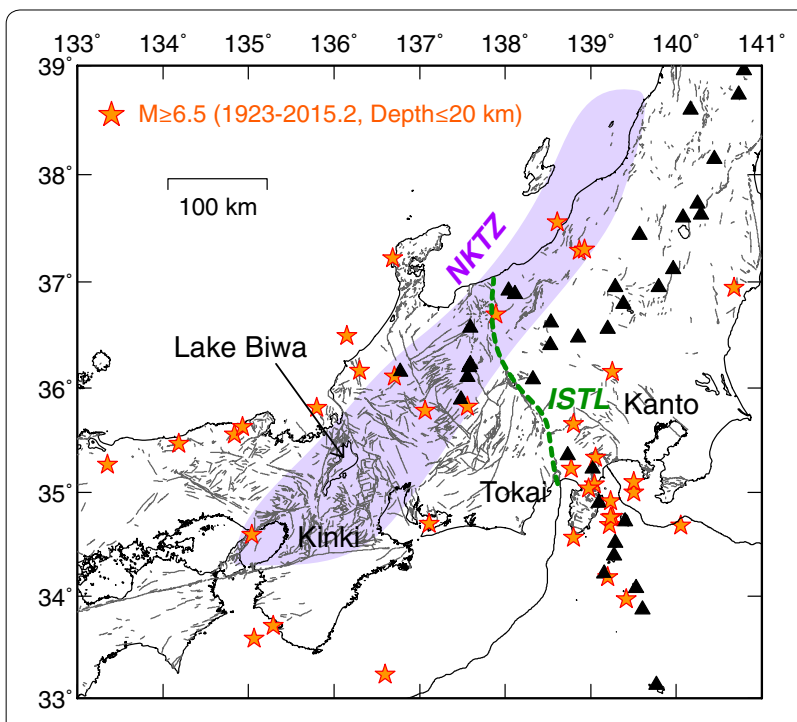

Fig. 1 Tectonic setting of central Japan. The Niigata-Kobe Tectonic Zone (NKTZ) (Sagiya et al. 2000) is denoted by purple shading. Black triangles represent active volcanoes, and orange stars denote epicenters of earthquakes $(M \geq 6.5)$ that occurred at depths of $\leq 20 \mathrm{~km}$ during 1923-2015. Gray lines denote active faults. The Itoigawa-Shizuoka Tectonic Line (ISTL) is shown by green curve. Names of regions discussed in the text are labeled

brittle-ductile transition zone (Hiramatsu et al. 2010). These seismological observations obtained in the last decade all support the model by Iio et al. (2002, 2004), suggesting that concentrated deformation in the weakened lower crust plays a crucial role in the generation of high strain rates west of the ISTL.

Three-dimensional (3D) seismic velocity heterogeneities have enhanced our understanding of spatial variations in the elastic properties beneath high-strain-rate zones (e.g., Nakajima and Hasegawa 2007; Okada et al. 2014). However, the anelasticity associated with such zones is poorly understood. Anelasticity derived from intrinsic seismic attenuation is a key parameter for evaluating ongoing viscoelastic deformation in the lower crust below high-strain-rate zones and mature fault systems (e.g., Eberhart-Phillips et al. 2014; Eberhart-Phillips 2016). Here we estimate the 3D P-wave attenuation $\left(Q_{p}^{-1}\right)$ structure in central Japan using waveform data recorded by a dense nationwide seismic network. We use a threestep approach developed by Nakajima et al. (2013) to delineate the $3 \mathrm{D} Q_{\mathrm{p}}^{-1}$ structure, which can minimize the potential trade-offs among unknown parameters. The corner frequency $\left(f_{\mathrm{c}}\right)$ of each earthquake is first estimated by the S-coda spectral ratio method. Next, we perform a joint inversion for the attenuation term $t^{*}$ and site amplification factors. Finally, the values of $t^{*}$ are inverted for the $3 \mathrm{D} Q_{\mathrm{p}}^{-1}$ structure (e.g., Rietbrock 2001). The obtained attenuation model is discussed in the context of the deformation patterns observed within the NKTZ.

\section{Data and methods}

\section{Corner frequency}

We used velocity waveform data from 8300 earthquakes $(2 \leq M \leq 5)$ with focal depths shallower than $350 \mathrm{~km}$ that occurred between October 2006 and February 2015 (Fig. 2a), and calculated spectral amplitudes of S-wave codas in $10 \mathrm{~s}$ time window taken at twice the theoretical S-wave travel time for a one-dimensional seismic velocity model (Hasegawa et al. 1978). Spectral ratios were calculated at common stations for earthquake pairs with a magnitude difference $\geq 0.5$ and an inter-event distance $\leq 40 \mathrm{~km}$. We then fitted an $\omega^{2}$ source model (Brune 1970) to the averaged spectral ratio in the frequency range of $1-32 \mathrm{~Hz}$ and determined values of $f_{\mathrm{c}}$ for the earthquake pair by a grid search with $f_{\mathrm{c}}$ steps of $0.2 \mathrm{~Hz}$. Figure $3 \mathrm{~b}$ shows an example of $f_{\mathrm{c}}$ estimation procedure for an earthquake pair. Values of $f_{\mathrm{c}}$ were estimated to be 5.2 and $15.4 \mathrm{~Hz}$ for $M 3.5$ and $M 2.4$ earthquakes, respectively. Standard errors of $f_{\mathrm{c}}$ evaluated by a bootstrap method with 1000 bootstrap samples were $0.27 \mathrm{~Hz}$ for the M3.5 earthquake and $1.12 \mathrm{~Hz}$ for the M2.4 earthquake (Fig. 3c). We applied this procedure to available earthquake pairs and determined a pair of $f_{\mathrm{c}}$ values. When five or more $f_{\mathrm{c}}$ values were obtained from different pairs for an earthquake, we calculated the average $f_{\mathrm{c}}$ and used the value in the subsequent analysis. The total number of the earthquakes with $f_{\mathrm{c}}$ estimates was 4718 (Fig. 2a).

\section{Attenuation term and site amplification factor}

For the earthquakes with $f_{\mathrm{c}}$ estimates, we calculated $\mathrm{P}$-wave and noise spectral amplitudes from vertical component of velocity seismograms with a window length of $2.56 \mathrm{~s}$ after and before the P-wave onset, respectively. We limited our analysis to a frequency range with signal-tonoise ratios of $\geq 3$. Frequency-dependent attenuation was assumed to obey the relationship

$$
t^{*}(t)=t_{0}^{*} f^{-\alpha},
$$

where $t_{0}^{*}$ is the attenuation term at $1 \mathrm{~Hz}$ (Stachnik et al. 2004). We used $\alpha=0.27$ because $\alpha=0.2-0.3$ has been estimated for the crust and the uppermost mantle beneath the Japanese Islands (Nakajima et al. 2013; Nakajima 2014; Saita et al. 2015) and this value range is the most appropriate value for the mantle (e.g., Jackson et al. 2002). We constructed a set of observation equations for multiple earthquakes at a single station and carried out a simultaneous inversion for $t_{0}^{*}$ and relative site amplification factors (for details, see Nakajima et al. 2013). As values of $f_{\mathrm{c}}$ estimated by the coda spectral ratio technique were for $\mathrm{S}$ waves, we calculated values of $f_{\mathrm{c}}$ for $\mathrm{P}$ waves by assuming the relationship $f_{\mathrm{cp}}=1.33 \times f_{\mathrm{cs}}$ (Uchida et al. 2007). An example of spectral amplitudes observed at three stations for a single earthquake (EQ1) is shown 


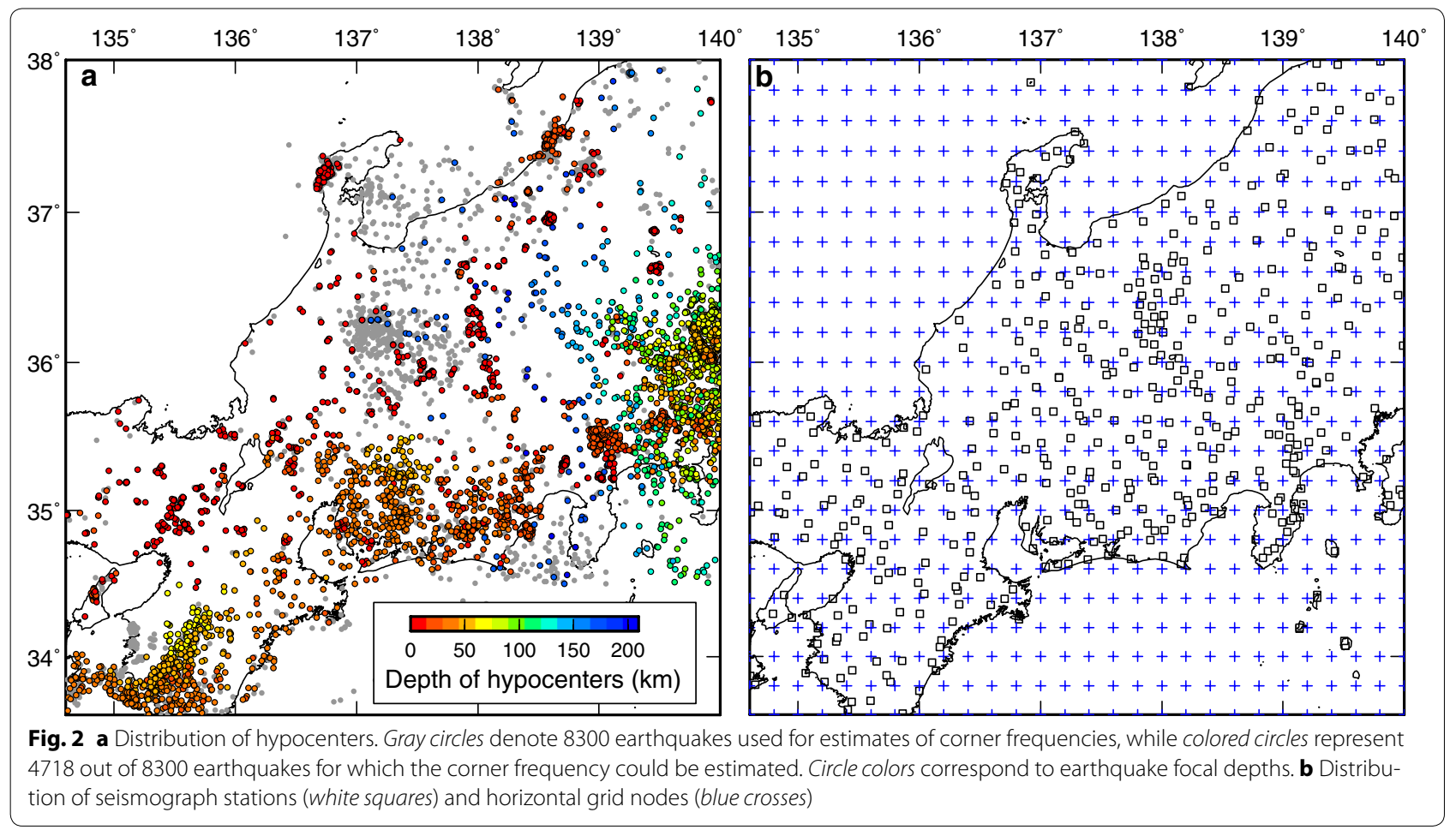

in Fig. 3d. Observed spectral amplitudes (blue curves in Fig. 3d) are reproduced by theoretical spectral amplitudes (red curve) that incorporated the estimated $t_{0}^{*}$, site amplification factors, and the $\omega^{2}$ source model. Relative site amplifications estimated for the three stations are shown in Fig. 3e.

\section{Tomographic inversion}

The $3 \mathrm{D} Q_{\mathrm{p}}^{-1}$ structure was determined by the inversion of $247,595 t_{0}^{*}$ values observed at 455 stations. It is noted that $Q_{\mathrm{p}}^{-1}$ values estimated in this study correspond to those at $1 \mathrm{~Hz}$. We calculated ray paths and travel times based on the 3D P-wave velocity model of Nakajima and Hasegawa (2007) with the ray tracing technique of Zhao et al. (1992a). In the inversion, we used a model parameterization identical to that in Nakajima and Hasegawa (2007), where crustal discontinuities (Zhao et al. 1992b) and the upper boundary of the Pacific slab (Nakajima et al. 2009) were considered, adjacent horizontal grid nodes were spaced at intervals of $0.2^{\circ}$, and vertical nodes were spaced at intervals of $5-50 \mathrm{~km}$ (Fig. 2b). We set initial values of $Q_{\mathrm{p}}^{-1}$ to be 0.0033 for the crust and mantle wedge, and 0.001 for the Pacific slab, and selected a damping parameter of 100 based on a trade-off curve between the root mean square (RMS) residuals of $t_{0}^{*}$ and model variance. Final results were obtained after four iterations; $t_{0}^{*}$ RMS residuals decreased from $0.036 \mathrm{~s}$ in the initial model to $0.015 \mathrm{~s}$.

We carried out two checkerboard resolution tests to assess the reliability of tomographic results and confirmed that the obtained results are reliable beneath the land area at a depth of $<40 \mathrm{~km}$ (see Additional file 1). We hereafter discuss the tomographic results in wellresolved, unmasked areas in Fig. 4, where recovery rates are greater than $20 \%$.

(See figure on next page.)

Fig. 3 Examples of estimates of corner frequency $\left(f_{c}\right)$, attenuation term $\left(t^{*}\right)$, and site amplification factors. a Map showing the locations of two earthquakes (red stars) and three stations (blue squares). EQ1 is an earthquake with M3.5 and a focal depth of $62 \mathrm{~km}$, and EQ2 is an earthquake with M2.4 and a focal depth of $46 \mathrm{~km}$. b S-coda spectral amplitude ratios for a pair of EQ1 and EQ2. Gray and blue lines denote spectral ratios for various common stations and the averaged spectral ratio, respectively. The red line denotes the theoretical spectral ratio that best fits the observations. Values of $f_{c}$ estimated for the two earthquakes are indicated by green lines with $f_{c}$ values. Inter-event distances $(D)$ and the number of common stations $(N)$ are shown in the panel. c Uncertainties in $f_{c}$ estimates evaluated by a bootstrap method. Histograms of $f_{c}$ for (left) EQ1 and (right) EQ2 are plotted from 1000 bootstrap samples, and standard errors of $f_{c}$ are $0.27 \mathrm{~Hz}$ for EQ1 and $1.12 \mathrm{~Hz}$ for EQ2. d Spectral amplitudes of observed P waves (blue curves) and noise (dashed curves). Red line represents the theoretical spectral amplitude calculated from the optimal value of $t_{0}^{*}$, site-amplification factors, and the $\omega^{2}$ source model. e Site amplification factors for the three stations 

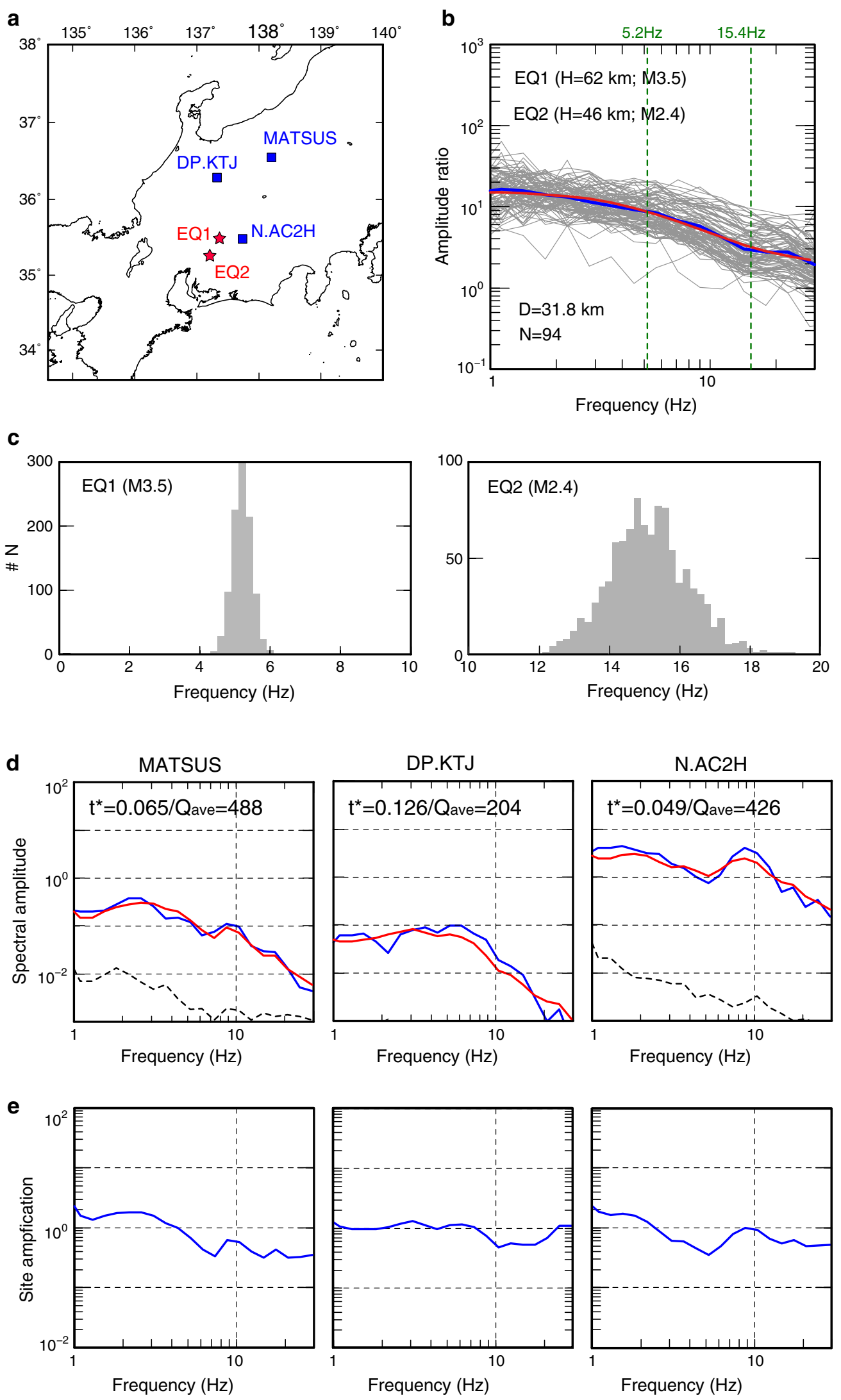


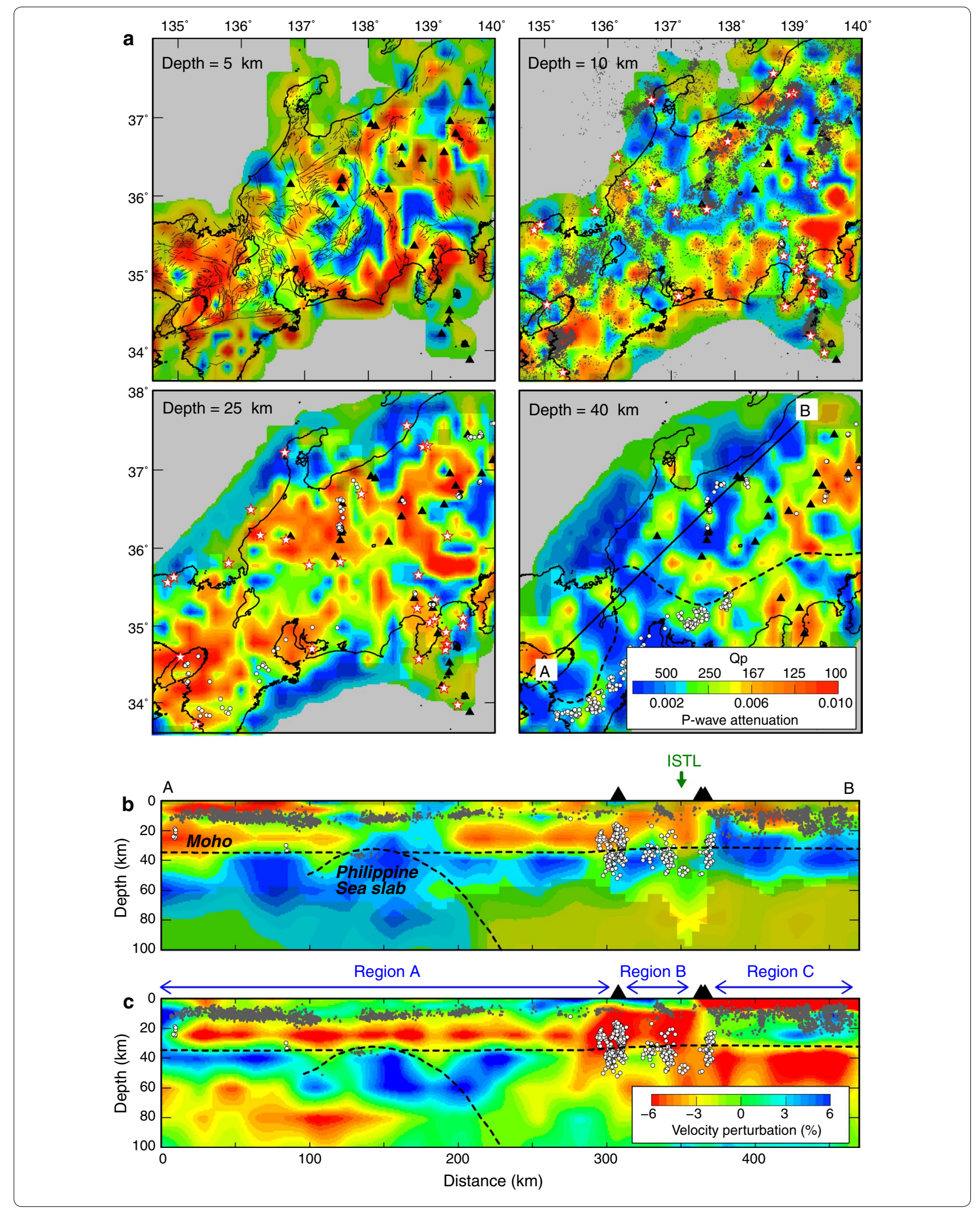


(See figure on previous page.)

Fig. 4 a Map showing $Q_{p}^{-1}$ at depths of 5, 10, 25, and $40 \mathrm{~km}$. The color scale is shown in the right bottom panel. Black triangles represent active volcanoes. Gray dots at a depth of $10 \mathrm{~km}$ represent earthquakes $(M \geq 1)$ in a depth range of 5-15 km in 2003-2015, and stars at depths of 10 and $25 \mathrm{~km}$ denote earthquakes $(M \geq 6.5)$ at depths of $\leq 20 \mathrm{~km}$ from 1923 to 2015. Deep low-frequency earthquakes that occur within $2.5 \mathrm{~km}$ of each depth slice are indicated by white circles. The black dashed line shows the $40 \mathrm{~km}$ iso-depth contour of the upper surface of the Philippine Sea slab (Hirose et al. 2008; Nakajima et al. 2009). Areas with recovery rates of $<20 \%$ for the two-grid-model of checkerboard resolution test are shaded in gray. b Vertical cross section of $Q_{p}^{-1}$ along line $A-B$ shown in the right bottom panel in a. Dashed lines indicate the Moho (Zhao et al. 1992b) and the upper surface of the Philippine Sea slab. The intersection of line $A-B$ with the ISTL is indicated by a green arrow. Black triangles at the top denote active volcanoes. Gray dots and white circles represent earthquakes $(M \geq 1)$ and low-frequency earthquakes, respectively, that occurred within $5 \mathrm{~km}$ of line $A-B$. c Vertical cross section of P-wave velocity perturbations along line $A-B$ (Nakajima and Hasegawa 2007). Other symbols are the same as in $\mathbf{b}$

\section{Tomography results}

The results show marked variations in $Q_{p}^{-1}$ with depth (Fig. 4a). At a depth of $5 \mathrm{~km}$, high-attenuation areas are distributed mainly in Kinki and Tokai districts, and around active volcanoes. In contrast, areas of moderate to low attenuation are dominant at a depth of $10 \mathrm{~km}$, even though isolated high-attenuation areas are observed in Kanto, Tokai, and Kinki districts. Seismicity in the upper crust and earthquakes with $M \geq 6.5$ (white stars in Fig. 4) tend to occur in areas of low to moderate attenuation. The lower crust, at a depth of $25 \mathrm{~km}$, shows high attenuation in Kinki, southeast of Biwa Lake, and around volcanic areas in the northern part of the study area. On the whole, the NKTZ shows high attenuation west of the ISTL, but there is a moderate- to low-attenuation area northeast of Biwa Lake, surrounded by high-attenuation areas.

Figure $4 \mathrm{~b}$ shows a vertical cross section of $Q_{\mathrm{p}}^{-1}$ along the NKTZ (line A-B shown in the panel for $40 \mathrm{~km}$ depth), and characterizes attenuation features in the crust of the NKTZ. Marked high-attenuation areas exist in the lower crust at horizontal distances of $0-120 \mathrm{~km}$ and $200-$ $300 \mathrm{~km}$, while the lower crust shows low attenuation east of the ISTL at distances of $>370 \mathrm{~km}$. In volcanic areas located at horizontal distances of $300-370 \mathrm{~km}$, highattenuation areas extend continuously from the lower crust to the surface. The resolution of the uppermost mantle is not sufficient to discuss the observed attenuation structure, as a result of an insufficient number of rays propagating at depths $>60 \mathrm{~km}$, where the recovery of the checkerboard resolution tests is not good (Fig. 4b; Additional file 1: Figure S1).

\section{Discussion}

One of the most striking features revealed by this study is the segmentation of the NKTZ derived from the attenuation structure in the crust. Nakajima and Hasegawa (2007) proposed that the NKTZ can be divided into a non-volcanic area (region A), a volcanic area (region B), and an area east of the ISTL (region C) (Fig. 4c). The distribution of $Q_{\mathrm{p}}^{-1}$ along the NKTZ correlates well with that of $\mathrm{P}$-wave velocity perturbations $(\mathrm{dVp})$ in the sense that high-attenuation areas correspond to low-velocity areas and vice versa (Fig. $4 \mathrm{~b}, \mathrm{c}$ ). The correlation coefficient between $Q_{\mathrm{p}}^{-1}$ and $\mathrm{dVp}$ at a depth of $25 \mathrm{~km}$ is calculated to be -0.47 with a probability value of $\sim 10^{-7}$, indicating a moderately weak but statistically significant negative relationship.

To the east of the ISTL (region C), the upper crust shows high attenuation and low velocity, while the lower crust shows low attenuation and moderate to high velocity (see dark symbols in Fig. 5), which differentiates seismic characteristics of the lower crust west of the ISTL. The highattenuation, low-velocity upper crust probably reflects a thick ( $6 \mathrm{~km})$ accumulated basin fill (e.g., Sato 1994). Seismic anisotropy derived from shear-wave splitting analysis reveals that the anisotropy east of the ISTL is structurally induced, which can be explained by intense faulting and folding in the sedimentary basin (Hiramatsu et al. 2010).

The volcanic area (region B) shows high attenuation and low velocity throughout the crust. High attenuation in this area is also suggested from S-wave attenuation studies (e.g., Carcole and Sato 2010; Liu and Zhao 2015) and lowfrequency $(1-4 \mathrm{~Hz})$ coda-wave attenuation (e.g., Jin and Aki 2005; Hiramatsu et al. 2013). As Vp/Vs values in the lower crust are high ( 1.85; Nakajima and Hasegawa 2007) and a low-resistivity body has been reported at depths of 20-30 km (e.g., Ogawa and Honkura 2004), we infer that the existence of magmatic fluids is responsible for the high-attenuation and low-velocity anomalies. The magmatic fluids probably originate from dehydration-related fluids in both the Philippine Sea and Pacific slabs (Nakamura et al. 2008). The possibility of the upward migration of slab-derived fluids is supported by high ${ }^{3} \mathrm{He} /{ }^{4} \mathrm{He}$ ratios ( 8 Ra) (Umeda et al. 2013). The absence of apparent high-attenuation areas beneath the Moho is probably due to the insufficient number of rays propagating through the uppermost mantle, as a consequence of small number of deep-focus earthquakes with reliable $f_{\mathrm{c}}$ estimates; this inference is supported by the poor recovery rates of the checkerboard patterns at depths of $>60 \mathrm{~km}$ (Fig. 4b).

On the whole, the lower crust beneath region A shows a marked low-velocity and high-attenuation anomaly (Fig. 4b, c). Since heat flow measurements do not suggest high-temperature conditions within the NKTZ 

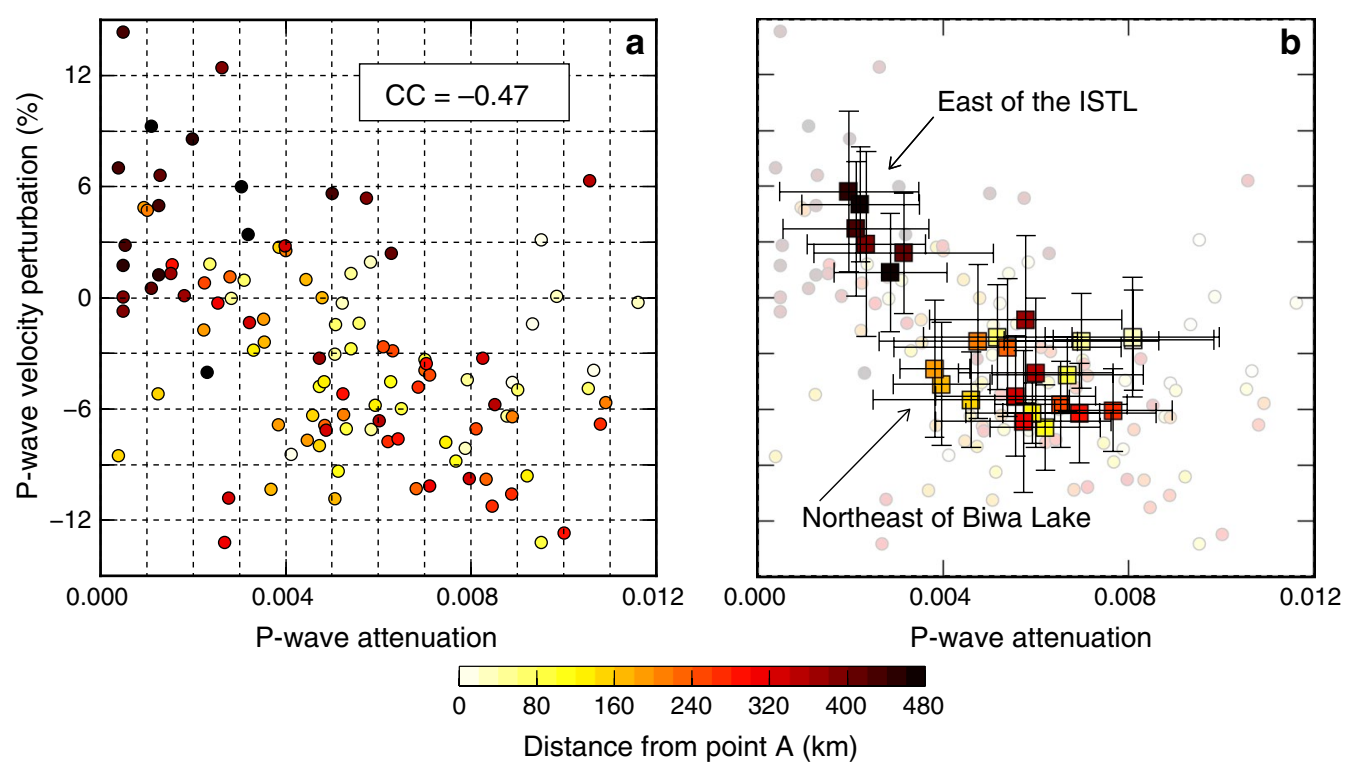

Fig. 5 a Relationship between P-wave attenuation values obtained in this study and P-wave velocity perturbations (Nakajima and Hasegawa 2007) at a depth of $25 \mathrm{~km}$ for each grid node located beneath the NKTZ (purple shading in Fig. 1). The number of grid nodes shown is 109 . The crosscorrelation coefficient for the two data sets is -0.47 . Colors represent the distance along the NKTZ calculated from point $A$ in line $A-B$ (Fig. 4). b Relationship between P-wave attenuation values obtained in this study and P-wave velocity perturbations that are averaged at every $20 \mathrm{~km}$ along line A-B. Bars denote 1-sigma uncertainties

(Tanaka et al. 2004), the presence of aqueous fluids probably results in reduced seismic velocities and enhanced seismic attenuation (Toksöz et al. 1979). However, a low-attenuation area exists at horizontal distances of $130-180 \mathrm{~km}$, where the Philippine Sea slab is in contact with the continental Moho (Fig. 4b). It is known that a temperature decrease by $\sim 100{ }^{\circ} \mathrm{C}$ reduces seismic velocity by only $\sim 1 \%$ (e.g., Duffy and Anderson 1989), but attenuation in olivine could be halved under upper mantle conditions (e.g., Jackson et al. 2002). Although few systematic experiments have investigated the temperature dependence of seismic attenuation in lower crustal materials, we infer that the lower crust locally cooled by shallow-angle subduction of the Philippine Sea slab is the primary cause of the low to moderate seismic attenuation values observed in this part of the crust. The inferred low-temperature conditions in the crust northeast of Biwa Lake are supported by deep cutoff depths of crustal earthquakes (Omuralieva et al. 2012).

The depth variations in the anelastic structures can qualitatively account for regional variations in the width of the high-strain-rate zone. A narrow $(25-40 \mathrm{~km}$ wide) zone of surface deformation on the Echigo plain (Nishimura et al. 2012), east of the ISTL, is probably due to the shallow deformation of the thick, anelastically weakened sediment. In contrast, the NKTZ west of the ISTL, which has a width of $\sim 100 \mathrm{~km}$, is caused by high rates of anelastic deformation in the lower crust, as proposed by Iio et al. $(2002,2004)$. It is likely that long-term regional tectonic stresses promote anelastic deformation in the weakened lower crust and that strain rates enhanced by the deformation reduce grain size of minerals (Platt and Behr 2011). The highly attenuated lower crust observed beneath the NKTZ west of the ISTL is probably affected by grain size reduction due to localized, high-strain-rate deformation, because grain size reduction enhances seismic attenuation (Jackson et al. 2002). One important implication of our attenuation model is that surface deformation northeast of Biwa Lake, where the lower crust shows moderate to low attenuation, would differ from that of other parts of the NKTZ, because marked anelastic deformation of the lower crust is unlikely to occur in this region.

Spatial variations in the weakness of the lower crust would cause spatial gradients in anelastic deformation rates, and stress could be consequently concentrated in the overlying brittle layer. The occurrence of many $M \geq 6.5$ earthquakes in the upper crust, below which anelastic properties in the lower crust vary sharply (Fig. 4a), may be one of the manifestations of high stress concentration in the brittle upper crust. While it is considered that reduction in the effective normal stress on a fault as a result of the supply of overpressurized fluids plays key roles in facilitating crustal earthquakes (e.g., Sibson 1992; Hasegawa et al. 2005; Yoshida et al. 2014), our observations add growing body of evidence that anelastic deformation in the lower crust is equally important in seismogenesis in the upper crust. 


\section{Conclusions}

This study characterizes seismic attenuation structures in central Japan and discusses spatial relationship between attenuation structures and surface deformation along the NKTZ. The anelastically weakened lower crust west of the ISTL promotes surface contraction over a region $\sim 100 \mathrm{~km}$ wide, while anelastic deformation in the shallow, thick sedimentary layer west of the ISTL causes a narrow region of surface deformation. Our observations can explain qualitatively the regional variations in the width of the high-strain-rate zone across the ISTL. The attenuation structure revealed in this study provides practical and important constraints on quantifying subsurface deformation, which is essential to constructing realistic models of seismogenesis in high-strain-rate zones.

\section{Additional file}

Additional file 1. Figure S1. Result of cherckerboard resolution tests for $\mathbf{a}$ the one-grid model and $\mathbf{b}$ the two-grid model. See text for details.

\section{Abbreviations}

NKTZ: Niigata-Kobe Tectonic Zone; ISTL: Itoigawa-Shizuoka Tectonic Line.

\section{Authors' contributions}

JN performed data processing and tomographic inversions. Both JN and TM designed this study and contributed to the interpretations and preparation of the manuscript. Both authors read and approved the final manuscript.

\section{Author details}

${ }^{1}$ Earth and Planetary Sciences, School of Science, Tokyo Institute of Technology, Tokyo, Japan. ${ }^{2}$ Research Center for Prediction of Earthquakes and Volcanic Eruptions, Graduate School of Science, Tohoku University, Sendai, Japan.

\section{Acknowledgements \\ We used waveform data recorded at a nationwide seismograph network. All the figures in this paper were plotted using GMT (Wessel and Smith 1998). Constructive reviews by T. Yamada and an anonymous reviewer improved the manuscript. This work was supported by JSPS KAKENHI Grant Numbers JP16H04040, JP16H04071, JP26109002 and JP26109006, and by the Ministry of Education, Culture, Sports, Science, and Technology of Japan, under its Observation and Research Program for the Prediction of Earthquakes and Volcanic Eruptions}

\section{Competing interests}

The authors declare that they have no competing interests.

\section{Data availability}

The data that support the findings of this study are available from the corresponding author on request.

Received: 11 January 2017 Accepted: 13 February 2017

Published online: 22 February 2017

\section{References}

Brune JN (1970) Tectonic stress and spectra of seismic shear waves from earthquakes. J Geophys Res 75:4997-5009

Carcole E, Sato H (2010) Spatial distribution of scattering loss and intrinsic absorption of short-period $\mathrm{S}$ waves in the lithosphere of Japan on the basis of the multiple lapse time window analysis of Hi-net data. Geophys J Int 180:268-290

Duffy TS, Anderson DL (1989) Seismic velocities in mantle minerals and the mineralogy of the upper mantle. J Geophys Res 94:1895-1912

Eberhart-Phillips D (2016) Northern California seismic attenuation: 3D Qp an Qs models. Bull Seismol Soc Am 106:2558-2573

Eberhart-Phillips D, Bannister S, Ellis S (2014) Imaging P and S attenuation in the termination region of the Hikurangi subduction zone, New Zealand. Geophys J Int 198:516-536

Hasegawa A, Umino N, Takagi A (1978) Double-planed structure of the deep seismic zone in the northeastern Japan arc. Tectonophysics 47:43-58

Hasegawa A, Nakajima J, Umino N, Miura S (2005) Deep structure of the northeastern Japan arc and its implications for crustal deformation and shallow seismic activity. Tectonophysics 403:59-75

Heki K, Miyazaki S (2001) Plate convergence and long-term crustal deformation. Geophys Res Lett 28:2313-2316

Hirahara K, Ando M, Hoso H, Wada Y, Nakano T (1998) Search for the movement of an active fault by GPS measurements. Earth Mon 225:149-153 (in Japanese)

Hiramatsu Y, Iwatsuki K, Ueyama S, lidaka T, the Japanese University Group of the Joint Seismic Observations at NKTZ (2010) Spatial variation in shear wave splitting of the upper crust in the zone of inland high strain rate, central Japan. Earth Planets Space 62:675-684. doi:10.5047/ eps.2010.08.003

Hiramatsu Y et al (2013) Spatial variation in coda Q and stressing rate around the Atotsugawa fault zone in a high strain rate zone, central Japan. Earth Planets Space 65:115-119. doi:10.5047/eps.2012.08.012

Hirose F, Nakajima J, Hasegawa A (2008) Three-dimensional seismic velocity structure and configuration of the Philippine Sea slab in southwestern Japan estimated by double-difference tomography. J Geophys Res 113:B09315. doi:10.1029/2007JB005274

lio Y, Sagiya T, Kobayashi Y, Shiozaki I (2002) Water-weakened lower crust and its role in the concentrated deformation in the Japanese Islands. Earth Planet Sci Lett 203:245-253

lio Y, Takeshi S, Kobayashi Y (2004) Origin of the concentrated deformation zone in the Japanese Islands and stress accumulation process of intraplate earthquakes. Earth Planets Space 56:831-842. doi:10.1186/ BF03353090

Jackson I, Fitz Gerald JD, Faul UH, Tan BH (2002) Grain-size sensitive seismic wave attenuation in polycrystalline olivine. J Geophys Res 107(B12):2360. doi:10.1029/2001JB001225

Jin A, Aki K (2005) High-resolution maps of coda Q in Japan and their interpretation by the brittle-ductile interaction hypothesis. Earth Planets Space 57:403-409. doi:10.1186/BF03351825

Liu X, Zhao D (2015) Seismic attenuation tomography of the southwest Japan arc: new insight into subduction dynamics. Geophys J Int 201:135-156

Nakajima J (2014) Seismic attenuation beneath Kanto, Japan: evidence for high attenuation in the serpentinized subducting mantle. Earth Planets Space 66:12. doi:10.1186/1800-5981-66-12

Nakajima J, Hasegawa A (2007) Deep crustal structure along the Niigata-Kobe Tectonic Zone, Japan: its origin and segmentation. Earth Planets Space 59:e5-e8. doi:10.1186/BF03352677

Nakajima J, Hirose F, Hasegawa A (2009) Seismotectonics beneath the Tokyo metropolitan area: effect of slab-slab contact and overlap on seismicity. J Geophys Res 114:B08309. doi:10.1029/2008JB006101

Nakajima J, Hada S, Hayami E, Uchida N, Hasegawa A, Yoshioka S, Matsuzawa T, Umino N (2013) Seismic attenuation beneath northeastern Japan: constraints on mantle dynamics and arc magmatism. J Geophys Res Solid Earth. doi:10.1002/2013JB010388

Nakamura H, Iwamori H, Kimura J-I (2008) Geochemical evidence for enhanced fluid flux due to overlapping subducting plates. Nat Geosci 1:380-384

Nishimura T, Suito H, Kobayashi T, Tobita M (2012) Crustal deformation in and around the Echigo plain clarified by geodetic observation across the Niigata-Kobe Tectonic Zone. Zisin 64:211-222 (in Japanese with English abstract)

Ogawa Y, Honkura Y (2004) Mid-crustal electrical conductors and their correlations to seismicity and deformation at Itoigawa-Shizuoka Tectonic Line, Central Japan. Earth Planets Space 56:1285-1291. doi:10.1186/ BF03353352 
Ohzono M et al (2009) Strain accumulation process around the Atotsugawa fault system in the Niigata-Kobe Tectonic Zone, central Japan. Geophys J Int 184:977-990

Okada T et al (2014) Seismic velocity structure in and around the Naruko volcano, NE Japan, and its implications for volcanic and seismic activities. Earth Planets Space 66:114. doi:10.1186/1880-5981-66-114

Omuralieva AM, Hasegawa A, Matsuzawa T, Nakajima J, Okada T (2012) Lateral variation of the cutoff depth of shallow earthquakes beneath the Japan Islands and its implications for seismogenesis. Tectonophysics 518-521:93-105

Platt JP, Behr WM (2011) Grainsize evolution in ductile shear zones: implications for strain localization and the strength of the lithosphere. J Struct Geol 33:537-550

Rietbrock A (2001) P wave attenuation structure in the fault area of the 1995 Kobe earthquake. J Geophys Res 106:4141-4154

Sagiya T, Miyazaki S, Tada T (2000) Continuous GPS array and present-day crustal deformation of Japan. Pageoph 157:2303-2322

Sagiya T, Nishimura T, lio Y (2004) Heterogeneous crustal deformation along the central-northern Itoigawa-Shizuoka Tectonic Line fault system, central Japan. Earth Planets Space 56:1247-1252. doi:10.1186/BF03353347

Saita H, Nakajima J, Shiina T, Kimura J-I (2015) Slab-derived fluids, fore-arc hydration, and sub-arc magmatism beneath Kyushu, Japan. Geophys Res Lett 42:1685-1693

Sato H (1994) The relationship between late Cenozoic tectonic events and stress field and basin development in northeast Japan. J Geophys Res 99:22261-22274

Shimazaki K, Zhao Y (2000) Dislocation model for strain accumulation in a plate collision zone. Earth Planets Space 52:1091-1094. doi:10.1186/ BF03352336

Sibson RH (1992) Implications for fault-valve behavior for rupture nucleation and recurrence. Tectonophysics 211:283-293
Stachnik JC, Abers GA, Christensen DH (2004) Seismic attenuation and mantle wedge temperatures in the Alaska subduction zone. J Geophys Res 109:B10304. doi:10.1029/2004JB003018

Tanaka A, Yamano M, Yano Y, Sasada M (2004) Geothermal gradient and heat flow data in and around Japan (I): appraisal of heat flow from geothermal gradient data. Earth Planets Space 56:1191-1194. doi:10.1186/ BF03353339

Toksöz MN, Johnston DH, Timur A (1979) Attenuation of seismic waves in dry and saturated rocks: II. Mechanisms. Geophysics 44:691-711

Uchida N, Matsuzawa T, Ellsworth WL, Imanishi K, Okada T, Hasegawa A (2007) Source parameters of a M4.8 and its accompanying repeating earthquakes off Kamaishi, NE Japan: implications for the hierarchical structure of asperities and earthquake cycle. Geophys Res Lett 34:L20313. doi:10.1 029/2007GL031263

Umeda K, Kusano T, Ninomiya A, Asamori K, Nakajima J (2013) Spatial variations in ${ }^{3} \mathrm{He} /{ }^{4} \mathrm{He}$ ratios along a high strain rate zone, central Japan. J Asian Sci 73:95-102

Yoshida et al (2014) Pore pressure distribution in the focal region of the 2008 M7.2 Iwate-Miyagi Nairiku earthquake. Earth Planets Space 66:59. doi:10.1186/1880-5981-66-59

Zhao D, Hasegawa A, Horiuchi S (1992a) Tomographic imaging of P and S wave velocity structure beneath northeastern Japan. J Geophys Res 97:19909-19928

Zhao D, Horiuchi S, Hasegawa A (1992b) Seismic velocity structure of the crust beneath the Japan islands. Tectonophysics 212:289-301 